\title{
A CASE OF SO-CALLED ALCOHOLIC AMNESIA FOLLOWING PROLONGED STUPOR, TERMINATING IN RECOVERY AFTER RE-EDUCATION*
}

BY ALBERT C. BUCKLEY, M.D.

Assistant Physician, Friends' Asylum for the Insane, Frankford, Philadelphia; Clinical Professor of Mental Diseases, Medico-

Chirurgical College; Assistant Neurologist, Philadelphia General Hospital

$7 \mathrm{HE}$ condition here reported is that of a patient who, as the result of alcoholic excess, developed delusions of persecution and a state of hallucinatory excitement of short duration. This was followed by a state of stupor lasting nearly two years, from which he recovered, but with a total loss of the power of recollection. $\mathrm{He}$ also recovered from the memory disturbance after a process of re-education.

The term amnesia is commonly used in a broad sense to indicate a loss of memory. It has been made to include failures of memory, both temporary and permanent, whether characterized by a loss of certain kinds of memory, as in the amnesic aphasias; or by a loss of the power to recall memories of every kind, covering a definite period, or the entire life of the individual.

The amnesia manifested by the patient whose case is here described belongs to the transitory retrograde variety, and was general in that there was a loss of recollection of all events of the life of the individual - he remembered nothing up to a definite point. Nevertheless, he possessed a remarkable degree of tenacity of memory for all events which followed his comparatively abrupt psychic awakening. This was shown by his ability to recall and retain all recent events wnen once they were brought to his attention. The reeducation process was for him a laborious one, covering a period of many months, and to those who had the opportunity to observe him, it was a most interesting process.

*Read at the Meeting of the Philadelphia Psychiatric Society, May 12, 1911. 
The particular interest centered about the fact that the patient possessed no recollection of his experiences prior to and including the period of clouded consciousness; but he had no amnesia for those experiences which occurred after he passed into the state of comparatively clear state of mind, at which time his re-education began.

Furthermore, the case was of unusual interest to those who observed the condition, on account of the length of time covered by the stuporous state, and the state of ambulatory automatism. During this period the patient was regarded as suffering from a progressive alcoholic dementia, and the prognosis made accordingly. The comparative suddenness with which the change in mental state appeared, after an attack of acute digestive disorder, makes us recall the instances we have seen in which an accident, a carbuncle, or other acute physical disorder, has been followed in some forms of mental disease by a rapid recovery from the psychosis.

In addition to the above reasons, the fact that the patient made a most satisfactory recovery, after a period of tedious re-education effort, makes the case worthy of record

The following has been extracted from the history of the disorder, and the notes, as they were recorded during the course of the malady, and the re-education period:

The patient, a male, thirty-six years of age, by occupation a clerk, came under observation April 22, 1905.

Family History: Father dead, cause unknown. Mother living at the age of seventy-six. She had a "stroke" several years ago. No distinct neuropathic history obtained. Three children living and well.

Patient's History: The patient has been a heavy drinker for several years; has been subject to attacks of gastric disorder. Luetic infection denied. For a year previous to his admission he is said to have been acting queerly, and to have been more irritable than usual.

The pronounced mental change occurred in February, 1905 , after drinking a large quantity of champagne on a wager. The night of the excessive indulgence, while on the way home, he became excitable, thought the police were after him, and that he had seduced a young girl.

When admitted to the hospital he was in a state of ex- 
citement, was pugnacious, made an attempt to get away from the attendants. He was partly oriented, as shown by the statement that he "ought not to be in a crazy house." Within a few hours after admission he passed into a state of stupor. The following day he suffered an attack of syncope, during which he became almost pulseless. Upon recovering from this attack he continued in a stuporous state, lying with eyes open and fixed. He could not be roused sufficiently to give him food. Later, it was possible to feed him liquids, though he remained in the state of stupor, and made no effort to help himself.

Remaining in this state he occasionally took food when put to his lips, and swallowed without difficulty. At times he roused sufficiently to speak a few words, for example, rapidly repeating the word "water."

Most of the time he remained motionless, staring as if looking at one fixed spot on the ceiling.

It was not until he had been under observation a month that he was noticed turning on his side when about to sleep. When the arms were passively raised they immediately fell as soon as the support was removed. No attention was paid by him to those about him, he required attention to all his physical needs; bladder and rectum were incontinent.

July 11, 1905. For the first time in two months the patient spoke, saying, "What is the matter with me?" "Where in the devil am I?" After that he immediately lapsed into his former stuporous state. A few days later he asked what was his name and where he was, and again promptly lapsed into apparent stupor. On another occasion he asked, "When are you going to take me out of here?" When asked where he wanted to go, he replied, "To hell." During five months the patient spoke three times, made no effort to help himself, and remained in a stuporous condition most of the time.

September 30, 1905: Recently the patient made several attempts to move himself, but was unable to sit up unless supported. When placed in a chair he would immediately fall to one side or the other. He learned to sit erect by being placed in a chair in a corner, where his body would be supported by the adjacent walls. 
During the next month he learned to stand alone, and, very gradually, to walk with aid. He was able to sit up several hours daily. At this time it was noticed that he moved the head and eyes when in the recumbent position, the first movements observed, except occasional blinking of the eyelids.

November 18, 1905. Patient walked about without assistance, but only when placed in the standing position, and started in a given direction. He would then walk to the opposite wall, only to stand facing it until he was turned about.

January 20, 1906. In the presence of a nurse and a visitor the patient spoke a few intelligible sentences. The words were not recorded, but in substance he said that he wanted to speak but could not. His general condition continued unchanged for several months. In the mean time he learned to smoke a pipe, which, if filled and a lighted match placed over the bowl, he would puff as long as the pipe was in his mouth. If the pipe was not made ready for him and placed in his mouth he would hold it in his hand for an indefinite time. When visited by relatives he would look at them, at times would smile, but did not speak.

$\mathrm{He}$ was still unable to attend to any of his physical needs, except that he slowly learned to feed himself to the extent that when food was placed before him and a spoon in his hand, he would help himself. Occasionally he would begin spontaneously to eat with his fingers.

For about a year his general condition was unchanged, until he had an attack of abdominal pain with vomiting, refusal of food, and offensive diarrhea, which lasted about a week. For several weeks he took food sparingly, and occasionally he vomited, after giving evidence of abdominal pain. He drank freely of water, often going for it himself and drinking directly from the faucet. When taken to the table he would sit with his arms hanging by his side, and the head dropped with the chin resting on the sternum.

January 4, 1907. Yesterday, while the patient was being assisted in dressing, he spoke to the attendant, for the first time in about eleven months. He asked for "some water," and, when urged to go to the dining-room he asked to "be excused." 
Although this was not the first time that the patient had spoken since he passed from the condition of excitement to that of stupor, it was the first time that he gave evidence of recognizing his relation to his environment. It was clear that the patient did not know where he was, but his manner of reaction when spoken to, although he did not answer, was distinctly different from that which characterized his reaction to external stimulation the previous day.

The patient did not speak again until evening. During an attempt to get him to speak by questioning him closely for a time he seemed unable to answer, simply looked at his questioner, and appeared confused.

Finally, in reply to questions concerning why he had not been able to talk, the patient replied, "It's funny how it all came."

When asked, "What came?" he remained silent for a few moments and finally replied, "You know."

It was impossible to get him to answer further any questions which might have thrown some light upon his mental state, so it was decided to try to get him to respond to questions concerning his recent pain and apparent discomfort. When asked why he did not eat, he promptly said that he could not "keep it down." When asked how his stomach felt, he promptly replied "hot." Further than this he did not speak during the first day.

January 5, 1907. The patient took no food, drank freely of water; during the morning he vomited.

That day he was asked by a nurse whether he would like to go home to see his wife and family. Previous to this the patient had not mentioned his family, but now promptly replied that he would like to see them.

Later in the day, when the patient was visited by the writer, he asked if he might see his wife. The same evening when visited by his wife he at first was not able to speak, or at least he did not, but finally, when asked if he wanted to go home, he answered, "I want to go home, if for only ten minutes, to see what it is like." This was the longest sentence the patient had formed, and this he repeated several times. When assured that he would be allowed to go home he seemed at ease, but did not further express himself. 
January 6,1907 . The patient took a small amount of albumen water; he tried to retain coffee, but could not; he continued to complain of the "hot feeling" in his stomach.

When questioned further about his speech and memory he said that "three days ago was the first time I realized anything." When asked his name, he replied, "I can't tell; that's what I want to find out." Likewise he was unable to tell where he was or where he lived. To all such questions, he said, "I can't tell; that's what I want to find out." He stated that he thought that if he were to go home "to see what it is like," he could "get together." (Home was suggested to him on the previous day.) Later, when told that some one had come to take him home he gave evidence of pleasure and expressed his thanks for the opportunity.

January 7, 1907. The patient was reported as being very anxious to remain at home. (He was allowed to go to his home with the understanding that he was to return to the hospital the next day.) He returned, for examination on the second day, with the following result:

Q. "Where have you been?"

A. "Home, at No. - B - Street."

"Do you remember going home?"

"Yes."

"Do you recall anything before that?"

"Yes, the day before I went home."

"Do you recall anything being wrong with your stomach?"

"Yes, I could not keep anything on my stomach."

"Do you remember my talk with you the morning you went home?"

"Yes, you asked me my name, where I lived, and about my brother-in-law, Mr. X."

"When you reached home did things seem as if you had seen them before?"

"No, not until the next day."

"How did they seem then?"

"As if I had never been away. Hearing the family talk brought it back to me."

The patient was able to give his name and address, and 
to answer several questions, the subjects of which he had heard discussed during the two days he spent at home.

The condition of his memory is well defined by his following answers:

"Where were you born?"

"I cannot say. Somewhere in this state, I believe."

"How old are you?"

"I cannot say."

"Are you married?"

"Yes." (This he had been told.)

"When were you married?"

"I cannot say."

"Have you any children?"

"Yes."

"How many?"

"Three."

"How old are they?"

"I cannot say."

"Did you know your children when you first saw them after you went home?"

"Not at first.

"What day is to-day?"

"Tuesday."

What time were you here yesterday?"

"About four o'clock."

At this point Dr. C. entered the room. The patient was asked if he knew Dr. C., but he did not recognize him as ever having seen him before. He supposed that might be the other doctor, as he had heard them at home speaking of another doctor.

"What river runs through P.?"

"The Delaware."

"Is there any other river?"

"I don't know of any."

Patient names table when asked to do so. When shown a horn paper-cutter he cannot at first name it. $\mathrm{He}$ says that he has one at home. Says that it is made of bone, that it looks familiar. After a time he called it a "paper knife."

When given a child's picture book on animals he is able 
to read a few lines. When asked what he read a few minutes later he can give the essential idea. He cannot continue reading for more than a few minutes, giving the reason that something else comes into his head.

In regard to the earlier condition of the patient's memory for reading, the first trial at reading was made on the third day (January 7), after his partial psychic awakening. At that time he was able to reproduce with some effort impressions of written language, but what he read meant nothing to him until its meaning was explained. $\mathrm{He}$ also remembered what he read, but did not understand it unless explained at the time of first reading.

January 9, 1907. Yesterday he saw the barber who had shaved him for years. The first time he saw him the patient did not know him. The second time he recognized having seen the man a few days before, and was able to recall the man's first name and part of the last name. P. seems to remember all that is told him.

The patient was asked to write. Paper and writing tablet were placed on a table before him, but he does not make any offer to begin to write.

When asked whether he can write, he states that he had not thought about that; he had seen his son write his name the night before, but the patient had not noticed how it was done at the time.

After questioning the patient as to how it was done he is unable to tell, also is unable to begin.

"What is Dr. B. doing now?"

"He is writing."

"How does he do it."

"With a pencil and paper."

"There are the pencil and paper; now you write."

"I don't know how to begin."

Paper and pencil are handed to him; he still sits apparently thinking how he shall begin. When the name of the town in which he lives is shown him in writing he can read it, but is unable to write it from dictation or copy.

To-day the patient recognized Dr. C. as having met him yesterday.

That the patient possessed general ideas in some sub- 
jects and lacked detail was shown when he was asked what was the distance from his home to the place in which he was employed. He said, "About as far as from here to that house (pointing to the greenhouse).

He then promptly asks, "How would you measure distance?"

A foot rule was shown him in order that it might suggest the unit of measure. Such was not the case, however, for he only answered, "My boy has one like that; it is used for school purposes."

The first time the patient went to the office where he was employed he was not told that he had been there before. Nevertheless, he at once recognized the place as having seen it before, but it did not occur to him that it was the office in which he had been a part of the working force. He also says that his home seems familiar, but he is unable to recall any of his former experiences, or any occurrences which had taken place there before his attack. He was shown the typewriter and telephone, both of which he had used many times. He was not able to name either of them, could not tell their use, and had no recollection of ever having used them. He was shown the account books containing entries in his own handwriting. These, he said, seemed familiar to him, but he could not tell why.

January 10, 1908. To-day the patient succeeded in writing the name of his town. He had been practising it in the mean time. He reads simple sentences well and is able to recall what he had read.

Questioned as follows:

"In what year were you born?"

"I cannot say."

"What year is this?"

"1907, they tell me."

"Do you remember anything about any other year?"

"No, I do not."

"How old are you?"

"Thirty-six."

"Are you older or younger than your children?"

"Older."

"How is that." 
"I don't know, except that I am thirty-six and they are nine, eleven, and fifteen.

"What is the age of your youngest child?"

"Nine."

"Do you remember the time when your youngest child was born?"

"No."

"You say you have three children?"

"Yes."

"Have you always had three children?"

"I don't know, I suppose I must have had."

"You say you have a wife?"

"Yes."

"Have you always had a wife?" time."

"I can't say. I suppose I must have had one all the

"What relation are you to your children?"

"Father,"

"What relation is your wife to your children?"

"Their mother, they say."

"Have you a father?"

"I don't know."

At this time the patient appeared as if in deep thought. When asked what he was thinking about, he replied, "I am thinking whether I have a father."

In order to attract his attention from the last question, he was asked, "Do you remember anything you saw at the office yesterday?"

"Yes, a couple of desks. A high one. They are not all one." (Meaning that the office was divided into smaller rooms by partitions.)

January 14, 1908. He was shown a memorandum book containing entries in his own writing. This he did not recognize, but supposed that was what he "used to do." He now says that he has seen people use the telephone so that now he knows its use. Previous to that he was unable to name the instrument, and could not tell its use.

When the patient was questioned about a near relative, he replied that he had not thought of that person; as the patient expressed it, "that has not yet come into my mind." When 
asked whether he had any idea of that person's appearance, he was not able to say whether he would recognize him or not.

Patient was asked what the middle initial letter in his name indicated. This he was unable to tell, as no one had yet given him that information.

That he was unable to understand the significance of family names was clearly indicated by the following:

After writing his own name, which he had been taught the day before, he was asked, "Is your name S-?" "Yes." "Is your wife's name S-?" "Yes." "Is your son's name $\mathrm{S} \longrightarrow$ ? " Yes. I guess everybody's name is $\mathrm{S}$

January 15,1908 . To-day he is able to write the name of his town when a copy is placed before him, but is unable to write without the copy. He says that he cannot remember the letters.

He saw snow for the first time, as far as he remembered. He had been told of the fact that it was snowing when he was at home that morning. He did not understand what was meant until he was told to look out of doors, when he saw "it coming down." He could not give any idea of the nature of snow. He says that it is not rain because rain is wet. When some snow was brought indoors, and he watched it melt, he reasoned that the change was due to the fact that it was "warmer in the house," but could give no clear idea about the phenomenon of melting. That he remembered nothing of his boyhood was illustrated by the fact that when he was asked about one of his fingers which was deformed by an injury in early life, he was unable to tell anything in regard to the accident, but said that he would find out about that. When questioned about a city in which he had spent several years of his life he was unable to state whether he had ever been there or not. He had no idea of geographical location. When questioned about the points of the compass he showed that he lacked all knowledge concerning them. When told of "North," "South," etc., he said he had "not gone into that yet." When asked if he ever had gone to school he replied that he did not know, stating that he had not thought about that.

- March 7, 1908. Patient has gained a great deal of 
knowledge through reading; states that he finds a great deal of what he wants to know in the encyclopedia. He spends much of his time in that way. He has no trouble in remembering what he reads. He can write from dictation, but finds that there are many words which he cannot spell. He has learned sufficient in the past two months to enable him to carry on an intelligent conversation on the daily topics with which he has made himself familiar. If he is questioned upon any subject of which he is ignorant, he at once says that he has not yet heard of that. For example, when asked if he knows anything about the World's Fair of 1900, he replied, "No, but I have heard of the one in 1889 when the Eiffel tower was built."

Without further lengthening the case history, the above will be sufficient to furnish some conception of the mental status of the patient.

Referring to the process itself, Wundt ${ }^{1}$ states that memory arises by a union of ideational elements in such a way as to form a special idea which can be referred to an earlier impression. Again, memory is regarded as dependent upon impressibility and on retentiveness, and upon these depends the power of reproduction or recollection. We may express it as a complex process depending upon two processes, first the process of reception of impressions, and, second, the power to recall those impressions.

Our patient had received numberless impressions during his life, but at the moment of his awakening he was powerless to recall one of them. There was a time when he was incapable of receiving impressions, that is to say, when he was in a state of stupor and remained motionless, regardless of all external stimulation. There was also a period of several months' duration, when, although he was capable of receiving impressions, that is, when sensory stimuli were followed by motor reactions, he had not the ability to indicate that he was conscious of those impressions. During that second period all his acts appeared "automatic." He sat down when pushed into a chair; he got up only when helped to his feet; he walked when started, and continued walking until he came to an obstruction and could walk no farther.

${ }^{1}$ Wundt, Outlines of Psychology, 2d edition. 
The lapsed memories for the movements of his body, the kinesthetic memories, including those movements commonly called "automatic actions," commenced to return at the time he first sat up unassisted; his ideational memories, characterized by the psychic act of recollection were entirely wanting. $\mathrm{He}$ possessed no knowledge of himself whatever at the time of his awakening. All data acquired were solely dependent upon his experiences which followed his awakening, that is to say, impressions which were then, to him, equivalent to a repetition of his former forgotten experiences.

He required to be told that he had three children before he could apprehend the fact. At no time was he able to recall the idea he at one time had, namely, that he was the father of his children, nor did he recall the fact, even when he saw his children and was told of the fact. On account of his helpless state, in so far as recollection was concerned, he was compelled to accept as fact the evidence of others.

The only suggestion of apparent recollection of former impressions he gave was when for the first time he was shown how to write his name, and later, when he seemed to have forgotten how to form certain letters of the alphabet. He very rapidly learned to write his name and some other words without being conscious of having formerly known how to form the characters. If we consider that he also learned to use a knife and a fork instead of his fingers, without knowing that those articles as such existed, and without knowing how to name them until many months after he was given their names, we can easily see why he should learn to write with comparative ease. The writing of one's name is an automatic act which is done without the thought of how it is accomplished. In all other instances there was no such reduction in the length of time it.required for him to acquire a knowledge of his former experiences. Furthermore, the possession of those data did not enable him to recall, by association, other facts dependent upon those experiences. For example, when told for the first time that "it is snowing," he looked about the room instead of looking out of doors. He was forced to accept the fact as such, and to him it was an entirely new fact. He did not know it was snowing because the season was winter until he was given 
that information; he did not know that the snow was cold until he felt it and the fact was explained; he did not know that it was a form of moisture until he saw it melt, when he said that it had "turned into water," which he had seen the day before when it rained.

Following the history of the course of the disorder, one can see that the amnesia persisted for all data which had not been recalled for him by those familiar with his early experiences. Although those data, when brought to his attention, were not recognized, he had no difficulty in conserving and subsequently recalling his impressions. His memory for facts learned in this way was remarkably tenacious. During the first few days of the re-education period he experienced some difficulty in recalling a few facts. This appeared to be the result of defective power of attention; something else would come into his head, as he expressed it. Also, on account of the fact that he was receiving so many new experiences at that time he had difficulty in keeping track of them all. In spite of this apparent difficulty he learned with remarkable rapidity, and it was not long before both these obstacles disappeared. At no time was there any evidence of dementia. He could reason well; his deductions were logical and were carried out as far as his store of ideas would permit. Later he became keenly interested; he was anxious to acquire new data, and at each examination would relate with pleasure that which he had learned in the intervals. An interesting fact was observed in regard to his method of acquiring a vocabulary. Most individuals, it is said, recall visual perceptions with greater ease than auditory perceptions. ${ }^{1}$ Our patient proved to be an interesting exception to this, as was shown in his attempt to learn new words. Words written for him were not remembered as easily as when they were spelled for him audibly.

Finally the case presented an interesting and important medico-legal aspect. During the early part of the convalescent period, which extended over the space of several weeks, the patient had as yet learned of none of the conventionalities of life. All of his efforts were directed towards learning

'A. Kirkpatrick, Psych. Rev., 1894, cited by Bianchi, Text-book of Psychiatry, New York, 1906. 
concrete facts. Direct questioning clearly showed that the patient was unable to distinguish between right and wrong, in fact, he did not know the meaning of the words. The forensic importance of this feature of the case is self-evident and therefore does not call for any further discussion. 